\title{
EDITORIAL
}

\section{Zuyan SHEN}

\section{New changes for new year}

(C) Higher Education Press and Springer-Verlag 2009

After two year's developing, Frontiers of Architecture and Civil Engineering has made a great progress, which has become a window to demonstrate significant achievements made by Chinese and foreign scholars. Here, l'd like to share the achievements with all the members of editorial board and friends who have concerned us in the past all along; at the same time, I also give my heartfelt gratitude to them. It's just their support to be the key factor of the success of the journal.

To improve communications and exchanges between the scholars in different countries and to serve them better, we decided to shift our policy. According to the new policy, we shall publish a true international journal which will carry the latest achievements in theories and practices made by worldwide scholars and engineers.

Through the advanced publishing platform of Springer, the articles will be published on line first, to make sure that the study results will be published at top speed. Simultaneously, the journal will be available quarterly according to the discipline, i.e. architecture and urban planning; structural engineering; hydraulic engineering; and geotechnical engineering, to provide facilities for readers in different professional background.

New age needs innovation, like Li chi said:"day by day make it new". As Editor-in-chief, I hope these new changes will give the journal substantial vitality and I look forward to receiving submissions from scholars and engineers all over the world. I would greatly appreciate hearing your suggestions for the journal. I am confident that the journal will grow into a leading journal in the near future.

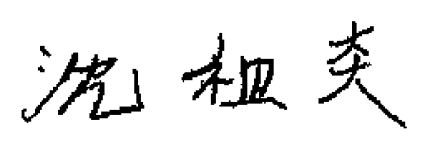

Editor-in-Chief 